Check for updates

Cite this: RSC Adv., 2019, 9, 27032

Received 21st June 2019

Accepted 19th August 2019

DOI: 10.1039/c9ra04665h

rsc.li/rsc-advances

\section{Isolation and identification of an antioxidant collagen peptide from skipjack tuna (Katsuwonus pelamis) bone $\uparrow$}

\author{
Ding Ding, $\$$ Bowei Du, $\$$ Chao Zhang, Fakhar Zaman and Yaqin Huang (D) *
}

To date, many researchers have developed active components that are derived from seafood processing for the purposes of healthcare. Here, an antioxidant collagen peptide was obtained from skipjack tuna (Katsuwonus pelamis) bone by using a combination of trypsin and chymotrypsin as the catalyst. The amino acid sequence of the peptide was identified as Ser-Ser-Gly-Pro-Pro-Val-Pro-Gly-Pro-MetGly-Pro-Met-Gly-Pro-Arg (SSGPPVPGPMGPMGPR) by liquid chromatography-electrospray ionization quadrupole time-of-flight mass spectrometry (LC-ESI-QTOF-MS) analysis. We found that the asprepared collagen peptide can efficiently scavenge DPPH radical ( $\mathrm{C}_{50} 3.149 \mathrm{mM}$ ), superoxide anion radical $\left(\mathrm{IC}_{50} 3.803 \mathrm{mM}\right)$ and $\mathrm{ABTS}$ radical $\left(\mathrm{IC}_{50} 9.489 \mathrm{mM}\right)$. In addition, it has been found that the methionine (Met) residue in the collagen peptide could provide a precise active site during the scavenging of DPPH radicals by Fourier transform infrared spectroscopy (FTIR) analysis and matrixassisted laser desorption/ionization time-of-flight (MALDI-TOF) mass spectrometry analysis. These results suggest that the peptide can find wide uses in the food, cosmetic and pharmaceutical industries.

\section{Introduction}

Oxidative stress, a vast threat to human health ${ }^{\mathbf{1 - 3}}$ results from an imbalance between the generation and scavenging of free radicals. ${ }^{4}$ Excessive free radicals attack membrane lipids, proteins and DNA and cause many health disorders, including diabetes mellitus, neurodegenerative disorders, cancer and inflammatory diseases. ${ }^{5-7}$ Currently, many researchers focus on developing functional foods to scavenge free radicals. ${ }^{8-10}$ As ingredients to such functional foods, antioxidant peptides have received much attention. ${ }^{\mathbf{1 1 - 1 4}}$

Researchers have tried to find antioxidant peptides from natural sources. Shazly et al. discovered that antioxidant peptides obtained from buffalo casein hydrolysates contain a number of antioxidant amino acids (Ser, Arg, Ala and Leu), and considered these to be key to the high radical scavenging potential of the hydrolysates. ${ }^{15}$ Blanca et al. identified an antioxidant peptide in fermented milk and discovered that the Met residue of the peptide is primarily responsible for the antioxidant activities of the peptide. ${ }^{\mathbf{1 6}}$

Beijing Laboratory of Biomedical Materials, Beijing Key Laboratory of Electrochemical Process and Technology for Materials, Beijing University of Chemical Technology, Beijing 100029, People's Republic of China. E-mail: huangyq@mail.buct.edu.cn; Fax: +86-10-64438266; Tel: +86-10-64438266

$\dagger$ Electronic supplementary information (ESI) available. See DOI: 10.1039/c9ra04665h

\$ These authors contributed equally to this work and should be considered co-first authors.
Fish collagen obtained from the byproducts of seafood processing usually contains a large number of antioxidant amino acids residues, such as Val, Met, Trp, Tyr, and Phe. ${ }^{17}$ Thus, people have been attempting to obtain antioxidant peptides from fish collagen. Wu et al. isolated an antioxidant peptide from the salmon skin collagen by using extracellular proteases from Vibrio sp. SQS2-3. ${ }^{18}$ Alemán et al. hydrolysed a squid collagen with alcalase to isolate a number of antioxidant peptides containing Leu residue which the authors speculated as playing an important role in the antioxidant activities of the peptides. ${ }^{19}$ Ngo obtained antioxidant collagen peptides from Nile tilapia and attributed the antioxidant activity of the peptides to the existence of non-aromatic amino acids such as Ala, Pro, and Val. ${ }^{20}$

Tuna (Thunnus spp.) and tuna-like species have long been significant sources of food for their high contents of bioactive proteins and unsaturated fatty acids. ${ }^{21}$ Currently, tuna generally is processed to produce raw flesh or canned food. Only about one-third of the whole tuna fish is used in the canning process, and the canning industry generates as much as $70 \%$ solid wastes from original fish materials. Waste includes viscera, gills, head, bone, and skin. In general, protein-rich by-products from the production of these tuna are processed into products with low market value, such as fishmeal and fertilizer. ${ }^{21}$ However, these byproducts could be used as functional food ingredients. Tuna protein hydrolysates (TPH), which are obtained through hydrolysis of the by-products of tuna processing, can be used as an ingredient in food industries to provide 
whipping, gelling, and texturing properties. Many researchers have attempted to derive antioxidant peptides from TPH. ${ }^{22-24}$

Trypsin (T) and chymotrypsin (C) are enzymes of the digestive system. Each enzyme is responsible for the hydrolysis of different peptide bonds. Trypsin hydrolyses the peptide and ester bonds formed by the carboxyl group of the basic amino acids, such as Arg and Lys. ${ }^{25}$ Chymotrypsin hydrolyses the peptide bonds formed by the carboxyl group of the aromatic or large hydrophobic amino acids, such as Phe, Tyr, Trp and Met. ${ }^{26}$ Here, antioxidant collagen hydrolysates from skipjack tuna (Katsuwonus pelamis) bone were prepared by using a combination of trypsin and chymotrypsin as the catalyst. We further purified the antioxidant peptides, determined their sequences and evaluated their antioxidant activities. We also investigated the mechanism of scavenging of free radicals by these peptides via experiments and molecular dynamics (MD) simulations.

\section{Experimental}

\section{Materials}

The frozen skipjack tuna bones were supplied by Xinfa Aquatic Food Co., Ltd. (Rongcheng, China). The frozen tuna bones were packed in zip-lock bags that were contained in a polystyrene box. The samples were transported to the Beijing University of Chemical Technology within $72 \mathrm{~h}$, and stored at $-20^{\circ} \mathrm{C}$. Trypsin $\left(2.50 \times 10^{4} \mathrm{U} \mathrm{g}^{-1}\right)$, chymotrypsin $\left(1.70 \times 10^{5} \mathrm{U} \mathrm{g}^{-1}\right)$, reduced glutathione (GSH), 2,2-diphenyl-1-picrylhydrazyl (DPPH), 2,2'azino-bis(3-ethylbenzthiazoline-6-sulfonic acid) (ABTS), diethylaminoethyl cellulose-52 (DEAE-52) and trifluoroacetic acid (TFA) were purchased from Aladdin Trading Co., Ltd. (Shanghai, China). Acetonitrile (ACN) was purchased from Thermo Fisher Scientific Co., Ltd. (Beijing, China). Synthetic peptides (SSGPPVPGPMGPMGPR, GEQGSTGPAGF, GFPGER, SSGPPVPGPGGPMGPR, purity > 99\%) were obtained from Botai Co., Ltd. (Shanghai, China). Human hepatocellular carcinoma (HepG2) cell line was obtained from the BeNa Culture Collection (BNCC, Beijing, China).

\section{Preparation of skipjack tuna bone collagen hydrolysates (STCHs)}

The bones were first demineralised using $1.0 \mathrm{M} \mathrm{HCl}$ solution at ambient temperature $\left(\sim 27^{\circ} \mathrm{C}\right)$ with a bone/solution ratio of $1: 2$ $\left(\mathrm{g} \mathrm{mL}^{-1}\right.$ ) for $12 \mathrm{~h}$, and the $\mathrm{HCl}$ solution was changed every $1.5 \mathrm{~h}$. The acid treated bones were washed with tap water and soaked in $4 \% \mathrm{NaCl}$ solution for $12 \mathrm{~h}$ to remove non-collagenous proteins. The pretreated bones were washed thoroughly with tap water and then subjected to a final wash with distilled water to remove any residual matter. Then tuna bone collagen was obtained.

We designed three sets of enzymatic hydrolysis experiments. One set involved a simultaneous addition of two enzymes at the trypsin and chymotrypsin (TC), while the other two sets involved the sequential addition of trypsin + chymotrypsin $(\mathrm{T}+\mathrm{C})$ or chymotrypsin + trypsin $(C+T)$. The enzymolysis conditions were shown in Table S1. $\dagger$ The enzymes were inactivated by heating at 90-95 ${ }^{\circ} \mathrm{C}$ for approximately $15 \mathrm{~min}$. The degree of hydrolysis (DH) was determined by the pH-state method. ${ }^{27}$ After filtering and drying, powders containing hydrolysates were obtained and used in subsequent investigations.

\section{Determination of amino acid composition of skipjack tuna bone collagen}

Amino acid analysis of collagen from skipjack tuna bone was performed using Hitachi L-8900 High Speed Amino Acid Analyzer (Tokyo, Japan) according to Liu and Sun. ${ }^{28}$

\section{Purification and identification of antioxidant peptides from STCH-TC}

Anion-exchange chromatography. A STCH-TC solution (5 $\mathrm{mL}, 30.0 \mathrm{mg} \mathrm{mL}{ }^{-1}$ ) was added into a DEAE- 52 cellulose column $(1.0 \times 60.0 \mathrm{~cm})$ that was pre-equilibrated with distilled water and stepwise eluted with distilled water and $\mathrm{NaCl}(0.1,0.5$ and

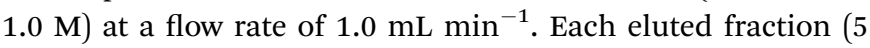
$\mathrm{mL}$ ) was collected and monitored at $280 \mathrm{~nm}$. Six fractions (Frac. 1, Frac. 2, Frac. 3, Frac. 4, Frac. 5 and Frac. 6) were collected and their DPPH radical scavenging activities were measured.

Reversed-phase high-performance liquid chromatography (RP-HPLC). Frac. 1 was dissolved in $1 \mathrm{~mL}$ TFA $(0.1 \%$, v/v) and separated by RP-HPLC (Agilent 1260 HPLC, Agilent Ltd., USA). Frac. 1 solution $\left(20 \mu \mathrm{L}, 1 \mu \mathrm{g} \mathrm{mL}^{-1}\right)$ was then injected into a Zorbax SB-C18 column ( $4.6 \mathrm{~mm} \times 250 \mathrm{~mm}$, Agilent, USA). The mobile phase, which was composed of A $(0.1 \%$ aqueous TFA (v/ $\mathrm{v})$ ) and $\mathrm{B}(\mathrm{ACN})$, was injected into the column according to a gradient program (2\% B from 0 to $10 \mathrm{~min}$ and $2-50 \%$ from 10 to $60 \mathrm{~min}$ ). The active fraction was isolated at a flow rate of 0.8 $\mathrm{mL} \mathrm{min}^{-1}$. The elution solution was monitored at $280 \mathrm{~nm}$ and collected, and their DPPH radical scavenging activities were measured.

Identification of the peptide sequence. The target peak fractions (27.6 $\mathrm{min}$ ) exhibiting the highest antioxidant activity were applied to LC-ESI-QTOF-MS analysis for sequence identification. The experiments were performed according to the method described by Piu et al. ${ }^{29}$

\section{Determination of antioxidant activity}

DPPH radical scavenging activity assay. The DPPH radical scavenging activity was measured using the method described by Kirby and Schmidt. ${ }^{30}$ One hundred microliters of each sample at different concentrations was added to $75 \mu \mathrm{L}$ of ethanol and $25 \mu \mathrm{L}$ of DPPH solution ( $0.2 \mathrm{mM}$ in ethanol) as a source of radicals. The mixtures were incubated for $1 \mathrm{~h}$ in the dark at room temperature. The scavenging capacity was assessed based on measurements at $517 \mathrm{~nm}$ using a microplate reader (SpectraMax® ${ }^{\circledR} 2 / \mathrm{M}^{\mathrm{e}}{ }^{\mathrm{e}}$, CA, USA). DPPH has an absorption peak at $517 \mathrm{~nm}$; when it is reduced by an antiradical compound, this absorption no longer occurs. Therefore, a lower absorbance for the reaction mixture indicated the presence of greater radical scavenging activity. The DPPH radical scavenging activity $\left(\mathrm{RSA}_{\mathrm{DPPH}}\right)$ was calculated using the following equation: 


$$
\mathrm{RSA}_{\mathrm{DPPH}}(\%)=\frac{A_{\text {control }}-A_{\text {sample }}+A_{\text {blank }}}{A_{\text {control }}} \times 100
$$

where $A_{\text {control }}, A_{\text {blank }}$, and $A_{\text {sample }}$ represent the absorbance of the control reaction (containing all reagents except the sample), the absorbance of the sample without DPPH solution and the absorbance of the sample in the presence of DPPH solution, respectively.

ABTS radical scavenging activity assay. The ABTS radical scavenging activity was investigated using a previously described method. ${ }^{31}$ Briefly, ABTS was produced via the reaction of ABTS stock solution ( $7 \mathrm{mM}$ ) with potassium persulfate (2.45 $\mathrm{mM})$. After incubation for $12-16 \mathrm{~h}$ in the dark, the ABTS solution was diluted with $0.2 \mathrm{M}$ phosphate buffer $(\mathrm{pH} 7.4)$ until its absorbance was approximately $0.70 \pm 0.02$ at $734 \mathrm{~nm}$. The ABTS radical scavenging activity in the samples was determined by mixing $30 \mu \mathrm{L}$ of each sample with $170 \mu \mathrm{L}$ of diluted ABTS solution. The absorbance was measured after 10 min of reaction. The ABTS radical scavenging activity $\left(\mathrm{RSA}_{\mathrm{ABTS}}\right)$ was calculated according to the following equation:

$$
\operatorname{RSA}_{\text {ABTS }}(\%)=\frac{B_{\text {control }}-B_{\text {sample }}+B_{\text {blank }}}{B_{\text {control }}} \times 100
$$

where $B_{\text {control }}, B_{\text {blank }}$, and $B_{\text {sample }}$ represent the control reaction (containing all reagents except the sample), the absorbance of the sample without ABTS solution and the absorbance of the sample in the presence of ABTS solution, respectively.

Superoxide anion radical scavenging activity assay. The superoxide anion radical scavenging activity of the synthetic peptides was determined using a previously described method. ${ }^{32}$ Aliquots $(80 \mu \mathrm{L})$ of peptide or GSH at different concentrations $(0-$ $5 \mathrm{mg} \mathrm{mL}^{-1}$ ) were mixed with $80 \mu \mathrm{L}$ of $50 \mathrm{mM}$ Tris- $\mathrm{HCl}$ buffer $(\mathrm{pH}$ 8.3) containing $1 \mathrm{mM}$ EDTA and $40 \mu \mathrm{L}$ of $1.5 \mathrm{mM}$ pyrogallol in $10 \mathrm{mM} \mathrm{HCl}$ in a 96-well microplate. After $10 \mathrm{~min}$ of incubation at room temperature, the superoxide anion radical-induced polymerization of pyrogallol was determined based on the increase of absorbance at $405 \mathrm{~nm}$ using a microplate reader. The superoxide anion radical scavenging activity $\left(\mathrm{RSA}_{\text {superoxide anion }}\right)$ was calculated according to the following equation:

$$
\mathrm{RSA}_{\text {superoxide anion }}(\%)=\frac{C_{\text {control }}-C_{\text {sample }}}{C_{\text {control }}} \times 100
$$

where $C_{\text {control }}$ and $C_{\text {sample }}$ represent the absorbance of the control reaction (containing all reagents except the sample) and the absorbance of the sample in the presence of all reagents, respectively.

Electron spin resonance (ESR) spectrometric assay. A typical reaction mixture that was used for the ESR spectrometric assay contained $1 \mathrm{~mL}$ of $1 \mathrm{mM}$ DPPH solution in ethanol and $1 \mathrm{~mL}$ of $5 \mathrm{mM}$ or $10 \mathrm{mM}$ sample. The concentration of the sample was determined based on ESR spectra that were obtained using an ESR spectrometer (JES FA-200, Japan) operating at the X-band frequency at room temperature.

Cell culture and treatment. The human hepatoma HepG2 cells were cultured in a MEM medium (CA, USA) including $10 \%$ of fetal bovine serum, $50 \mu \mathrm{g} \mathrm{mL} \mathrm{m}^{-1}$ of streptomycin and $50 \mathrm{U} \mathrm{mL}^{-1}$ of penicillin at $37{ }^{\circ} \mathrm{C}$ under $5 \% \mathrm{CO}_{2}$.
The cell culture and treatment were investigated using a previously described method. ${ }^{33}$ In detail, cell cytotoxicity was measured by using a tetrazolium salt WST-8 (Cell Counting Kit 8 , CCK-8). HepG2 cells $\left(6 \times 10^{3}\right.$ per well) were pretreated with the synthetic peptide (SSGPPVPGPMGPMGPR, GEQGSTGPAGF and GFPGER) at different concentrations ( 5 and $15 \mu \mathrm{M}$ ) in a 96well plate for $24 \mathrm{~h}$. After treatment with $500 \mu \mathrm{M}$ of $\mathrm{H}_{2} \mathrm{O}_{2}$ for $6 \mathrm{~h}$, $10 \mu \mathrm{L}$ of WST-8 was added and the mixture was incubated at $37{ }^{\circ} \mathrm{C}$ for $2 \mathrm{~h}$. Cell viability was calculated in the light of the absorbance at $450 \mathrm{~nm}$ by SpectraMax® ${ }^{\circledR} 2 / \mathrm{M}^{\mathrm{e}}$ (CA, USA).

\section{Determination of peptide structure}

Fourier transform infrared spectroscopy-attenuated total reflection (FTIR-ATR) spectrometry. The interaction of the SSGPPVGPMGPMGPR peptide with DPPH radicals was observed using a Nicolet 6700 FTIR-ATR (Thermo Nicolet, USA). The scans were performed in a spectral range spanning from $500 \mathrm{~cm}^{-1}$ to $4000 \mathrm{~cm}^{-1}$.

Secondary structure determination using circular dichroism (CD). Secondary structure analyses of the samples were performed using a Jasco J-810 circular dichroism spectroscope (Shimadzu, Japan) at room temperature. $200 \mu \mathrm{L}$ of peptide solution at a concentration of $0.1 \mathrm{mg} \mathrm{mL}^{-1}$ was added into a cell with a $0.01 \mathrm{~cm}$ optical path. The spectral range was $195-270 \mathrm{~nm}$, the resolution was $0.2 \mathrm{~nm}$ and the bandwidth was $1 \mathrm{~nm}$. A scanning speed of $100 \mathrm{~nm} \mathrm{~min}{ }^{-1}$ with a $2 \mathrm{~s}$ response time was used to scan each sample in triplicate.

\section{Determination of the molecular weights and sequences of the synthetic peptides}

The molecular weight distribution of the samples was analyzed using matrix-assisted laser desorption/ionization time-of-flight (MALDI-TOF) mass spectrometry. For the identification of the sequences, the synthetic peptides were applied to MALDI-TOF/ TOF mass spectrometry analysis (Ultraflextreme, Bruker, Germany).

\section{Modeling platform and simulations of peptide-DPPH radical complexes}

Molecular dynamics (MD) simulation was performed using Material Studio 6.0 software with a canonical (NVT) ensemble. A cubic box with a size of $47.43 \times 47.43 \times 47.43 \AA(x, y$, and $z$ dimensions) containing one peptide molecule and one DPPH radical molecule was built. Periodic boundary conditions were employed for all three dimensions of the box, and a PVFF force field was chosen to model the interactions among all the particles. A velocity scale thermostat was used to fix the temperature at $298 \mathrm{~K}$ with a $0.1 \mathrm{ps}$ decay constant. Energy minimization with integration (5000 steps) was first used to relax the molecules prior to the beginning of the simulation. The system was then equilibrated using a 5 ns MD simulation with a time step of $1 \mathrm{fs}$. 


\section{Statistical analysis}

All experiments were conducted in triplicate $(n=3)$ and the values were expressed as the mean \pm the standard deviation (SD). An ANOVA test was used to analyze the experiment data in SPSS 22.0 software (Statistical Program for Social Sciences, SPSS Corporation, Chicago, IL, USA).

\section{Results and discussion}

\section{Antioxidant peptides obtained from skipjack tuna bone}

For skipjack tuna bone collagen, the relative content of each amino acid residue in the bone collagen was determined (Table 1). We found that the antioxidant amino acids, such as Arg, Lys, Phe and Met, were present. By comparison, skipjack tuna bone collagen contains a higher ratio of Met residues than tilapia skin collagen. ${ }^{34}$

Researchers have previously demonstrated that the presence of Trp, Tyr, and Phe residues within the C-terminus of peptides appeared to be essential for radical scavenging, ${ }^{35}$ and those antioxidant peptides which contain Lys or Arg residues in the Cterminus have higher antioxidant activity. ${ }^{36}$ Therefore, based on the structure and amino acid composition of skipjack tuna bone collagen, we used a combination of trypsin and chymotrypsin as the catalyst to prepare collagen hydrolysate $(\mathrm{STCH}-$ TC) with high antioxidant activity. Actually, chymotrypsin cleaves peptide bonds on the carboxyl side of Phe, Tyr, and Try residues, and trypsin specifically cleaves peptides on the carboxyl side of Arg and Lys residues. Here, we studied the optimal conditions for the preparation of STCH-TC by implementing Box-Behnken Design (BBD) in combination with response surface methodology (RSM). At the same time, we prepared STCH-T + C and STCH-C + T as control samples to investigate the interaction between trypsin and chymotrypsin.

Table 1 Amino acid content in skipjack tuna bone collagen

Number of residues/1000 residues

\begin{tabular}{lrr} 
Amino acid & Skipjack tuna bone & Tilapia skin \\
\hline Asp & 46 & 48 \\
Thr & 30 & 24 \\
Ser & 37 & 35 \\
Glu & 77 & 69 \\
Gly & 337 & 347 \\
Ala & 125 & 123 \\
Val & 25 & 15 \\
Met & 15 & 9 \\
Ile & 13 & 8 \\
Leu & 27 & 23 \\
Tyr & 7 & 2 \\
Phe & 18 & 13 \\
Lys & 23 & 25 \\
His & 13 & 6 \\
Arg & 43 & 47 \\
Hyp & 70 & 79 \\
Pro & 94 & 119 \\
& &
\end{tabular}

The results are shown in Table S1.† STCH-TC exhibited much higher antioxidant activity than the control samples, indicating that there are synergistic effect between trypsin and chymotrypsin for the hydrolysis of skipjack tuna bone collagen. We believe that peptides with high antioxidant activity could be isolated from the STCH-TC.

As shown in Fig. 1A, six fractions (Frac. 1 to Frac. 6) were separated from STCH-TC using a DEAE-52 cellulose column. Frac. 1 exhibited the highest DPPH radical scavenging ratio $(23.41 \%)$ at $1 \mathrm{mg} \mathrm{mL}^{-1}$ (Fig. 1B). Thus, it was subsequently purified using RPHPLC (Fig. 1C). According to the elution profile obtained using RPHPLC, one major fraction with the highest DPPH activity $(22.09 \%)$ was identified (27.6 min) (Fig. 1D).

The peptides with the highest antioxidant activity were determined to reside in the main peak (27.6 min) obtained from Frac. 1 and were evaluated using LC-ESI-QTOF-MS analysis to identify antioxidant peptides. As shown in Table 2, the peptides with antioxidant activity were identified. We did not find any information on these peptides in the BIOPEP database. Previous studies have shown that there is at least one antioxidant amino acid residue (Val, Try, Tyr, Phe, Met, or His) within antioxidant peptide chains. ${ }^{37}$ Therefore, we believe the peptide (SSGPPVPGPMGPMGPR) which contains a Gly-Pro-Met (GPM) fragment from STCHTC could be an antioxidant peptide. In addition, the Arg residue in its $\mathrm{C}$-terminus may contribute to the antioxidant activity of the peptide.

\section{In vitro evaluation of antioxidant peptides}

The three peptides (SSGPPVPGPMGPMGPR, GEQGSTGPAGF and GFPGER) identified in the highly-antioxidant fractions from STCH-TC were synthesized (Fig. S1 $\dagger$ ). These peptides were selected to meet certain requirements, such as the presence of Phe residues at the C-terminus or the presence of Val, Met and Phe residues within the peptide chain. To evaluate the antioxidant activities of these three peptides, DPPH, superoxide anion and ABTS radical scavenging assays were performed, and their activities were compared with those of the GSH positive controls (0-1.0 mM). The $\mathrm{IC}_{50}$ values of $\mathrm{GSH}$ (as standards) during the inhibition of DPPH, superoxide anion and ABTS are $0.329 \mathrm{mM}$, $0.335 \mathrm{mM}$ and $0.105 \mathrm{mM}$, respectively (Fig. S2†).

One peptide (SSGPPVPGPMGPMGPR) exhibited higher $\mathrm{DPPH}$ radical scavenging activity $\left(\mathrm{IC}_{50} 3.149 \mathrm{mM}\right)$ than the other two peptides (no more than $25 \%$; Fig. $2 \mathrm{~A}$ ). The $\mathrm{IC}_{50}$ of the SSGPPVPGPMGPMGPR peptide was also lower than that of GPP $\left(\mathrm{IC}_{50} 7.16 \mathrm{mM}\right)$ and WDR ( $\mathrm{IC}_{50} 7.63 \mathrm{mM}$ ) derived from hydrolysates from bluefin leatherjacket and $S$. lewini proteins, respectively. ${ }^{38,39} \mathrm{DPPH}$ is a radical that contains an unpaired electron, which could capture a proton when it encounters antioxidants. Recently, it has been reported that the radical scavenging mechanism utilized by antioxidant peptides containing Met residues is single electron transfer (SET), ${ }^{40}$ which indicates that peptides containing Met residues may have high DPPH radical scavenging activity. In addition, the position of the antioxidant amino acid residues within peptide sequences also affects the antioxidant activity of the peptide, and 

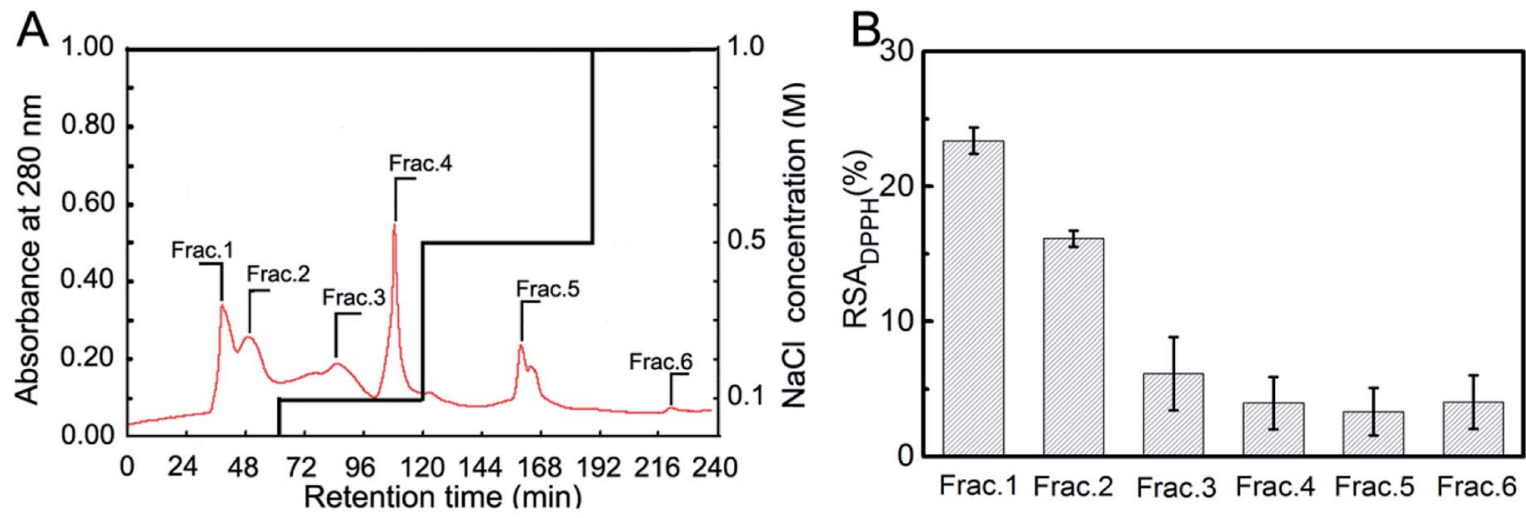

Frac.1 Frac.2 Frac.3 Frac.4 Frac.5 Frac.6
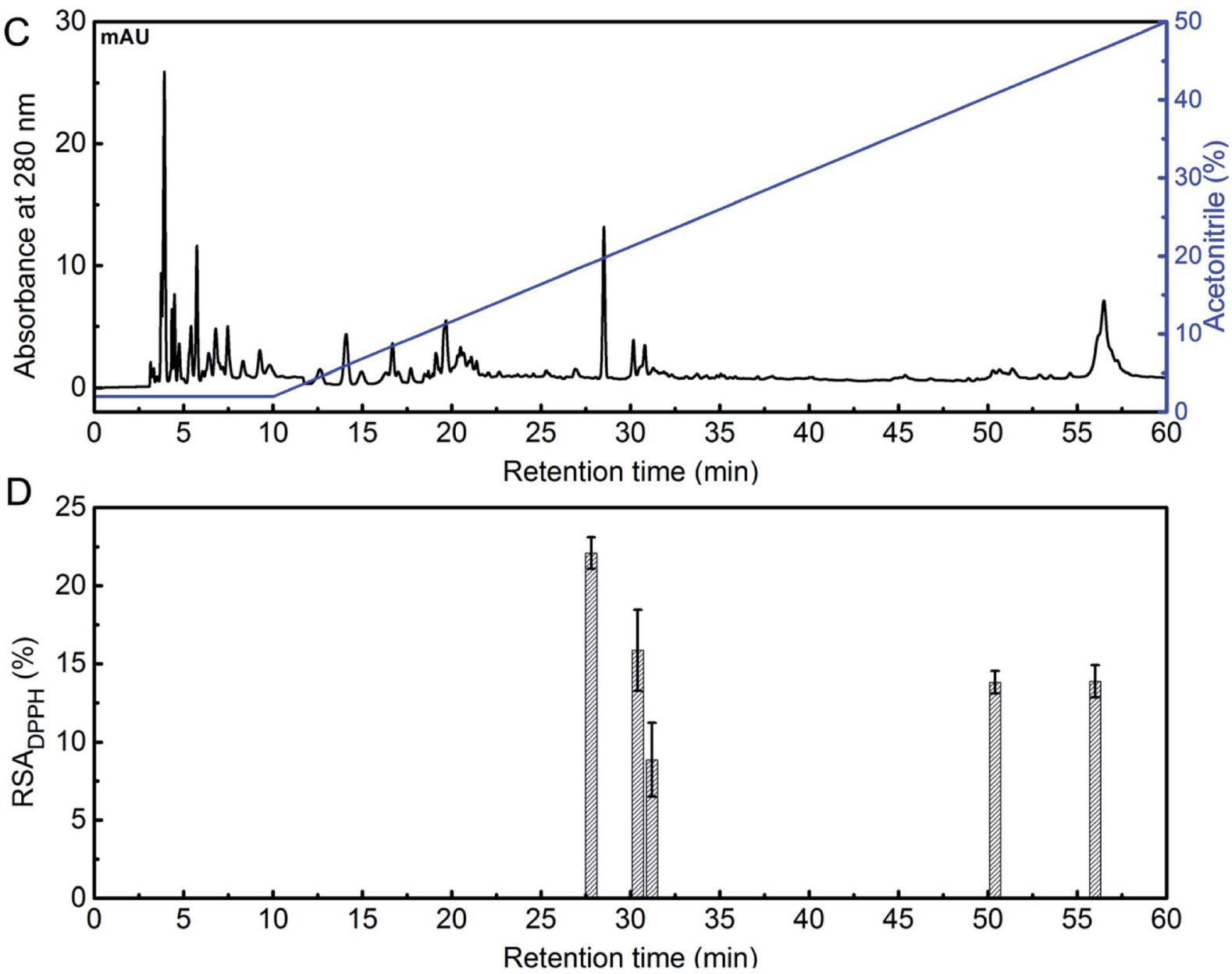

Fig. 1 (A) Elution profile of STCH obtained using DEAE-52 cellulose chromatography; (B) inhibition of DPPH radicals in the fractions was determined $\left(1 \mathrm{mg} \mathrm{mL}^{-1}\right)$; (C) elution profile of Frac.1 obtained using RP-HPLC; (D) DPPH radical scavenging activity of the active fraction based on the RP-HPLC chromatogram (1 $\left.\mathrm{mg} \mathrm{mL}^{-1}\right)$.

antioxidant peptides containing Lys and Arg residues at the Cterminus have higher antioxidant activity. ${ }^{36}$

From the Fig. 2B and $\mathrm{C}$, we observed that the SSGPPVPGPMGPMGPR peptide also exhibited high scavenging activity in the presence of superoxide anion radicals $\left(\mathrm{IC}_{50} 3.803\right.$ $\mathrm{mM}$ ) and ABTS radicals ( $\mathrm{IC}_{50} 9.489 \mathrm{mM}$ ). Thus, we inferred that the presence of Val, Arg and Met residues within a peptide sequence may be beneficial to its antioxidant activity. ${ }^{\mathbf{1 6}}$
The above results indicate that the SSGPPVPGPMGPMGPR peptide has high antioxidant activity. Using ESR measurements, the DPPH radical scavenging activity of the SSGPPVPGPMGPMGPR peptide was obtained. The changes in the ESR signal intensity of the SSGPPVPGPMGPMGPR at different concentrations are shown in Fig. 2D. The ESR signal intensities can be determined based on the peak height, which is the sum of the up-peak value and the downpeak value. ${ }^{41,42}$ For the SSGPPVPGPMGPMGPR peptide, the 
Table 2 The sequence of peptides identified by LC-ESI-QTOF-MS in the target peak fractions

\begin{tabular}{llll}
\hline Theo. $\mathrm{MH}^{+}[\mathrm{Da}]$ & Sequence & Ions score mascot & Location \\
\hline 1520.7348 & SSGPPVPGPMGPMGPR & 42 & $\mathrm{f}$ 159-175 \\
702.3570 & APDPFR & 35 & $\mathrm{f} 1195-1200$ \\
1327.6641 & GFPGLPGQSGEPGK & 33 & $\mathrm{f} 959-972$ \\
976.4371 & GETGPSGPAGF & 32 & $\mathrm{f} 791-801$ \\
830.4268 & GHRGFSGL & 29 & $\mathrm{f} 253-261$ \\
662.3257 & GFPGER & 27 & $\mathrm{f} 668-673$ \\
1007.4429 & GEQGSTGPAGF & 18 & $\mathrm{f} \mathrm{620-630}$
\end{tabular}

comparison between the signal heights of the blank and the samples in each ESR plot indicated that the decrease in the ESR signal intensity is $43.10 \%$ at a $5 \mathrm{mM}$ concentration and $79.7 \%$ at the $10 \mathrm{mM}$ concentration. In addition, upon searching the BLAST protein database, the sequence of this antioxidant peptide was only found in a few species of fish, almost all of which are uncommon.

In summary, the SSGPPVPGPMGPMGPR peptide not only has high bioactivity in terms of scavenging DPPH radicals, but could also be used to distinguish tuna collagen from other common collagens on the market. Some peptides with 3-9 amino acid residues have been found to have strong antioxidant activities. In fact, many factors affect the antioxidant activity of peptides, including the amino acid composition, amino acid sequence and spatial conformation. ${ }^{43}$ Nowadays, some antioxidant peptides with high molecular weight, such as NTDGSTDYGILQINSR and TVTSLDLPVLRW, have also been reported. ${ }^{44,45}$ The radical scavenging mechanism of the peptide SSGPPVPGPMGPMGPR is worth further exploring.

The HepG2 cell line is considered a good model with which to research in vitro toxicity of the liver, since it retains many of the specific functions that are characteristic of normal human hepatocytes. ${ }^{46}$ Prior to the evaluating the effect of the three peptides on scavenging free radicals, the cytotoxicity of the synthetic peptides in HepG2 cells was also assessed (Fig. 3). $\mathrm{H}_{2} \mathrm{O}_{2}$ at $500 \mu \mathrm{M}$ significantly decreased cell viability by $50.0 \%$. We found that pre-treatment of SSGPPVPGPMGPMGPR at concentration of 5 and $15 \mu \mathrm{M}$ significantly enhanced cell viability to $64.92 \pm 5.73 \%$ and $74.93 \pm 2.55 \%$, respectively. In contrast, the other two peptide can not reduce cytotoxicity induced by $\mathrm{H}_{2} \mathrm{O}_{2}$. In addition, we found that the three peptides have no toxic side effects on HepG2 cells (Fig. S4†). These results demonstrate that the peptide SSGPPVPGPMGPMGPR possess protective effect on $\mathrm{H}_{2} \mathrm{O}_{2}$-induced oxidative stress in HepG2 cell.

\section{DPPH radical scavenging mechanism utilized by antioxidant peptides}

The measurement of DPPH scavenging is a quick, convenient, and efficient method to determine antioxidant activity. Here, we
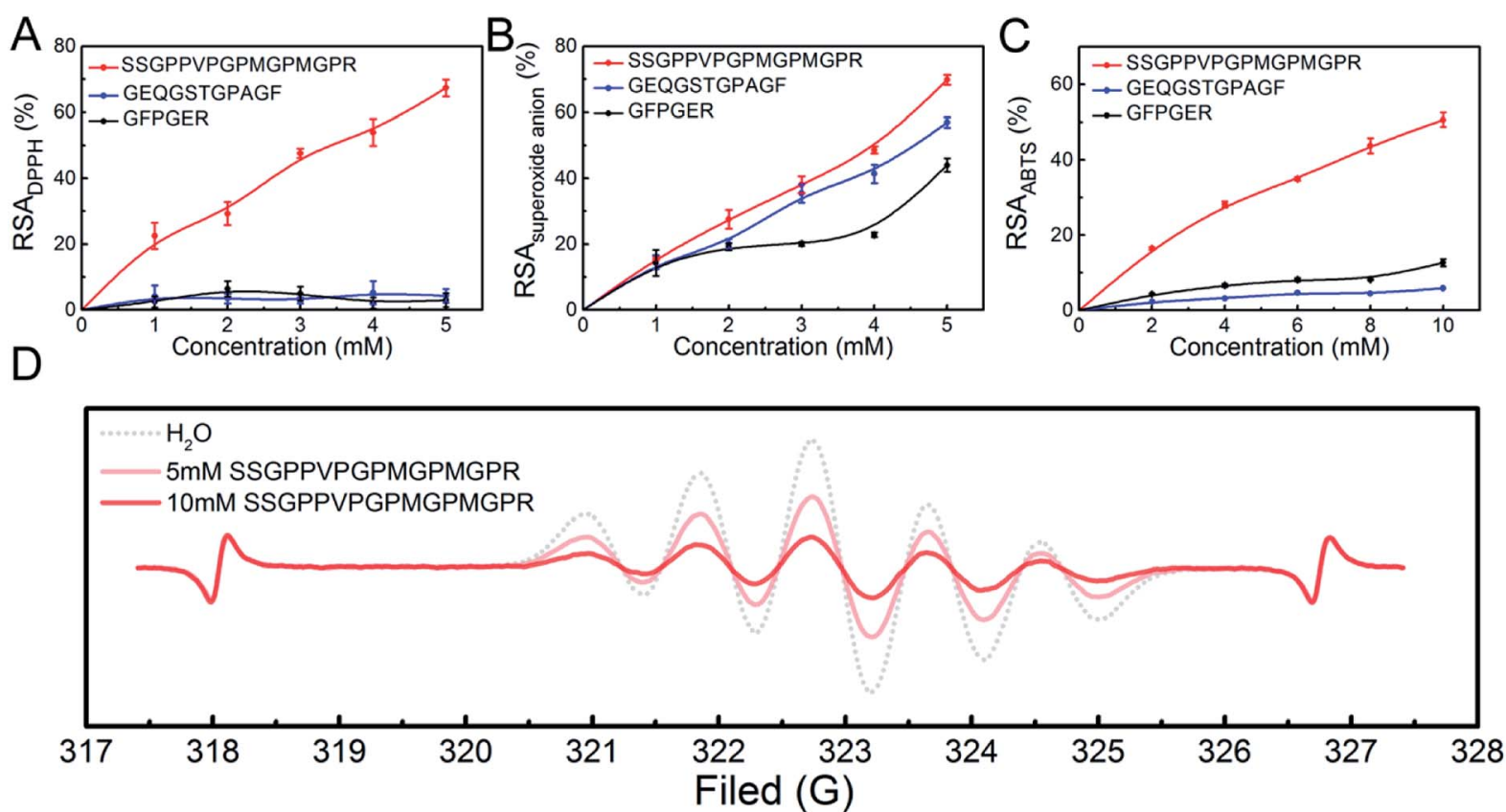

Fig. 2 Antioxidant activities of the peptides in terms of: (A) DPPH radical scavenging activity; (B) superoxide anion radical scavenging activity; (C) ABTS radical scavenging activity; (D) ESR spectra in the presence of DPPH radicals. 


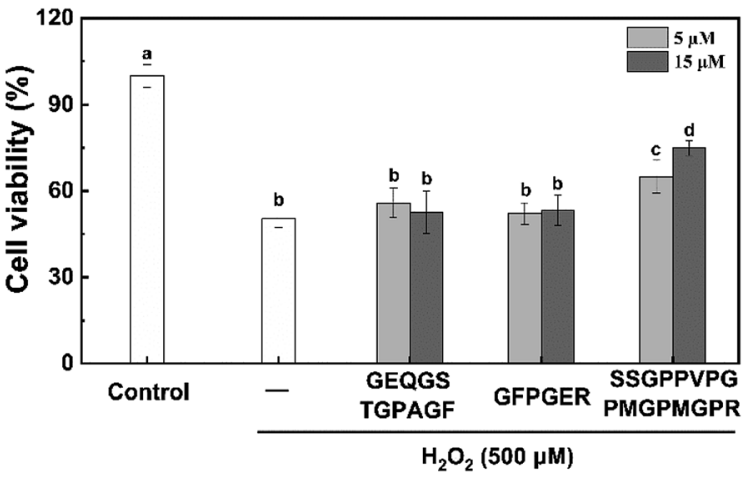

Fig. 3 Effects of the peptides on $\mathrm{H}_{2} \mathrm{O}_{2}$-induced cytotoxicity in $\mathrm{HepG} 2$ cells.

are interested to understand the mechanism utilized by the SSGPPVPGPMGPMGPR peptide during scavenging of DPPH radicals. Due to the complexity of the peptides and the lack of effective experimental methods, there are some challenges for exploring their radical scavenging mechanism. The secondary structure of peptides affects its biological activity, and it could be investigated by $\mathrm{CD}$. The $\mathrm{CD}$ spectra (Fig. 4A) of the SSGPPVPGPMGPMGPR peptide and the SSGPPVPGPMGPMGPR peptide in the presence of DPPH radicals exhibited one negative minimum at approximately $200 \mathrm{~nm}$, which is due to a random coil conformation. Although there are only slight differences between the curves generated for the SSGPPVPGPMGPMGPR and the SSGPPVPGPMGPMGPR peptides in the presence of DPPH radicals, the conformation of the SSGPPVPGPMGPMGPR peptide was altered after the reaction. After scavenging of DPPH radicals, the proportion of $\beta$-turns increases from $34.3 \%$ to $35.1 \%$, and the proportion of random coil increases from $46.5 \%$ to $47.6 \%$, while the proportion of $\beta$-sheets decreases from $15.1 \%$ to $13.9 \%$. After reacting with the DPPH radicals, the secondary structures of the peptides assumed a more relaxed conformation. Their FTIR spectra displayed similar curves between 4000 and $500 \mathrm{~cm}^{-1}$ (Fig. 4B). The $\mathrm{CH}_{3}$ stretching vibrations were blue-shifted from $2972.78 \mathrm{~cm}^{-1}$ to
$2925.04 \mathrm{~cm}^{-1}$. In addition, the emergence of an $\mathrm{S}-\mathrm{C}$ bond at $1056.14 \mathrm{~cm}^{-1}$ demonstrated that the structure of the Met residue was changed. These results indicate that there was a reaction between the Met residue and DPPH.

The products were measured using MALDI-TOF mass spectrometry (Fig. 5A). According to the mass spectra, the molecular weights of products were determined to be 1520.486 and 1472.466 Da, which indicated that a single novel product was present. To determine the changes in the amino acids residues that resulted in the decrease of the molecular weight, further MALDI-TOF/TOF mass spectrometry analysis was conducted (Fig. 5B and C). The results showed that the molecular weight of the Met residue was reduced by $48 \mathrm{Da}$, which is consistent with the decrease in the total molecular weight of the peptide. This means one of the Met residues in the SSGPPVPGPMGPMGPR peptide could play a key role in the scavenging of DPPH radicals. As the peptide contains two Met residues, only one serves as an active site during scavenging of DPPH radicals. It may be a result of a spatial configuration structure for the peptide.

We designed a peptide that could be used to verify the above results. Gly was selected to replace the reactive Met residues, resulting in a synthetic peptide with the sequence of SSGPPVPGPGGPMGPR peptide as a control sample. The results of the scavenging DPPH radical assay (Fig. 6A) showed that the DPPH radical scavenging activity of the SSGPPVPGPGGPMGPR peptide was lower than that of the SSGPPVPGPMGPMGPR peptide. The result further demonstrates that the Met residue plays an essential role during scavenging of DPPH free radicals.

The ESR results (Fig. 6B) showed that the inhibition potency of the SSGPPVPGPMGPMGPR peptide scavenging DPPH radical is $43.10 \%$, whereas that of the SSGPPVPGPGGMGPGR peptide scavenging DPPH radical is $29.78 \%$, which is consistent with the above results. We deduced that the sulfur in the Met residue reacts with DPPH radicals; the structure of the SSGPPVPGPMGPMGPR peptide is shown in Fig. 6C.

In addition to the sequences of the peptides, the configuration of the peptides also strongly affects their bioactivity. This may be the key reason why only one Met residue in the SSGPPVPGPMGPMGPR peptide contributes to the scavenging of DPPH free radicals. However, because of the limitations of
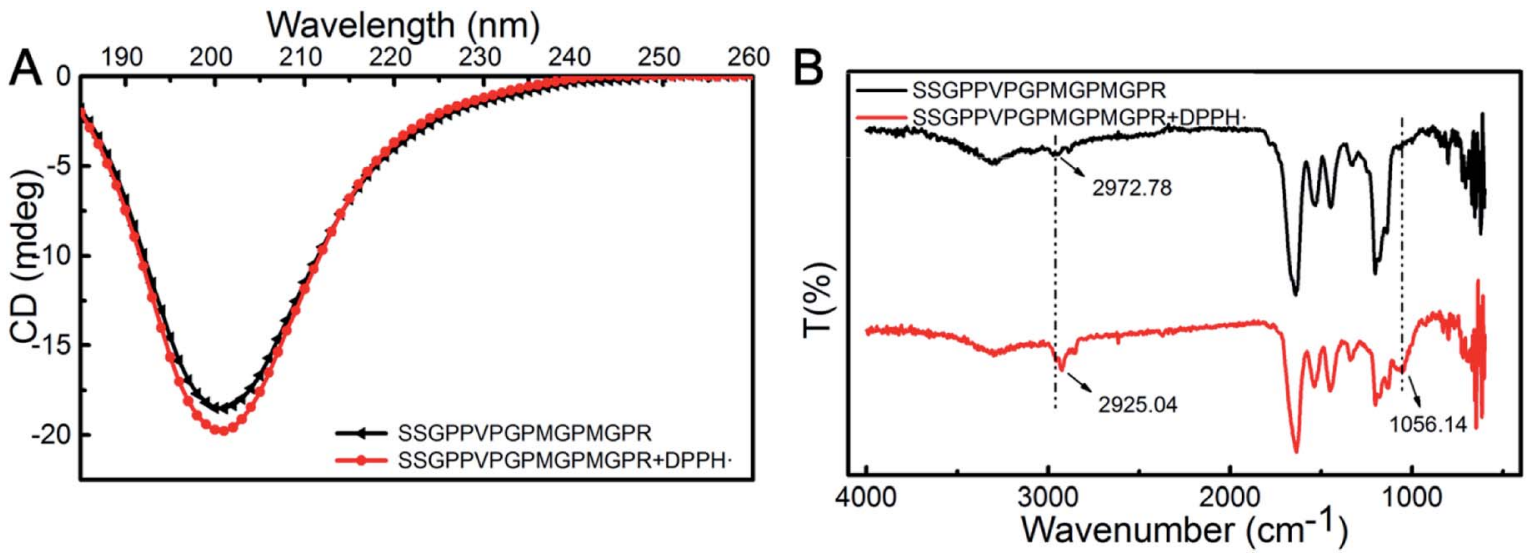

Fig. 4 The mechanism utilized by SSGPPVPGPMGPMGPR peptide during scavenging of DPPH radicals. (A) CD spectra; (B) FTIR-ATR spectra. 

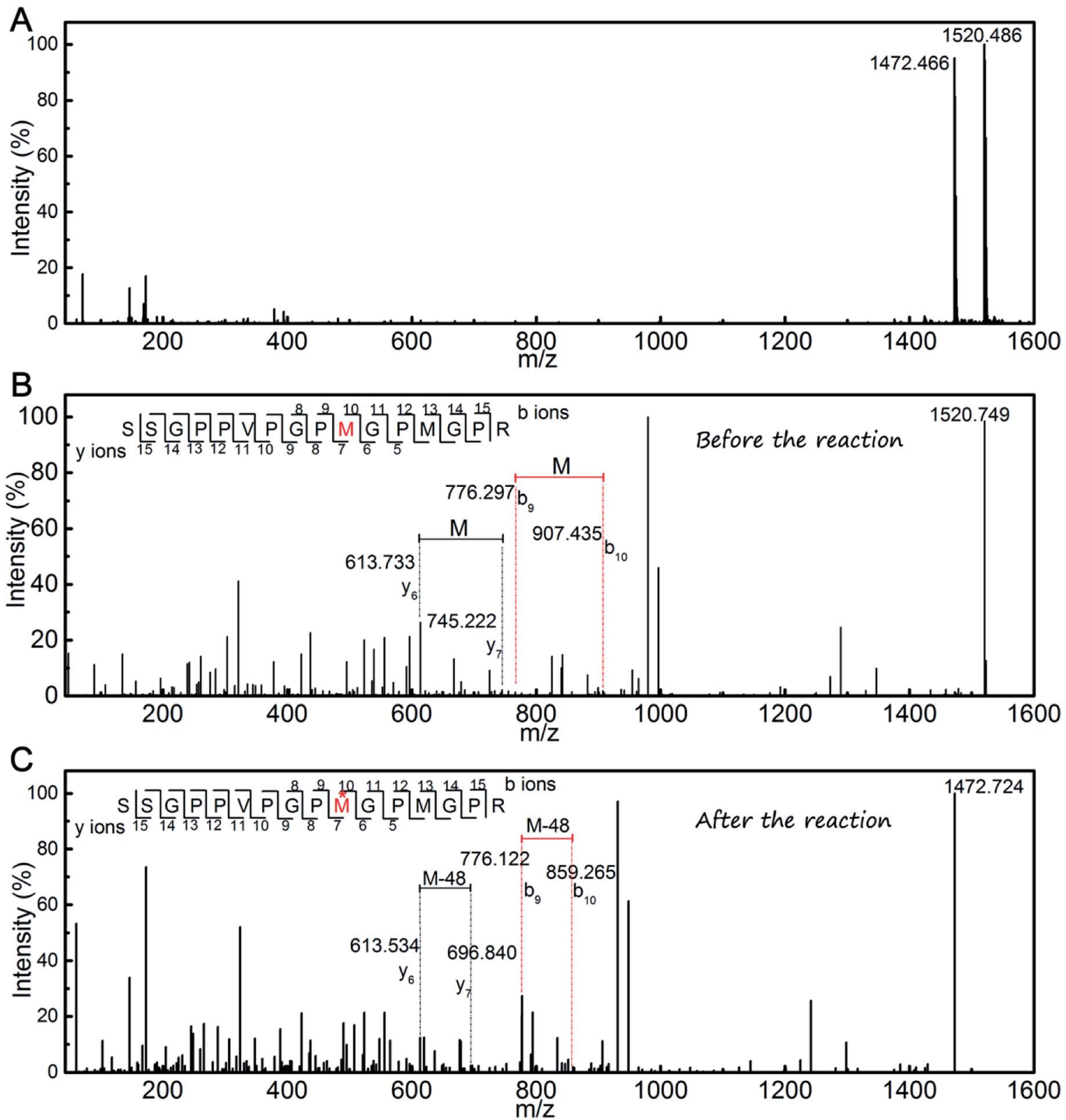

Fig. 5 (A) MALDI-TOF mass spectrometry of the SSGPPVPGPMGPMGPR peptide after the reaction with DPPH radicals; (B) MALDI-TOF/TOF mass spectrometry of the SSGPPVPGPMGPMGPR peptide; (C) MALDI-TOF/TOF mass spectrometry of the SSGPPVPGPMGPMGPR peptide after the reaction with DPPH radicals.

the experiment, the conformational structure of the peptide could not be observed directly. Therefore, a molecular dynamics (MD) simulation was used to explore the scavenging behaviour of the peptide. The conformational structure of the SSGPPVPGPMGPMGPR peptide in the presence of DPPH radicals was investigated. We placed one unfolded the SSGPPVPGPMGPMGPR peptide and one DPPH radical molecule in a box for the purposes of the simulation. The time variation of the potential energy of this system is shown in Fig. S5. $\dagger$ The initial potential energy was at a relatively high value and fluctuated within a large range. As the simulation progressed, the peptide folded and coalesced, and the corresponding potential energy decreased to a much lower value and was maintained at that level. This demonstrated that the curled peptide exhibited a higher stability than the unfolded peptide. In the curled peptide, the $\mathrm{S}-\mathrm{CH}_{3}$ bond in the Met residue, which is on top of a peptide clump and has been experimentally observed to be effective, is exposed to the environment (shown inside the red circle in Fig. $\mathrm{S} 5 \dagger$ ), while another Met residue, which is inside the peptide clump, would hardly contact with the dissociated radical. This phenomenon provides further insight regarding the important role of the Met residue in the SSGPPVPGPMGPMGPR peptide during the scavenging of DPPH radicals. 

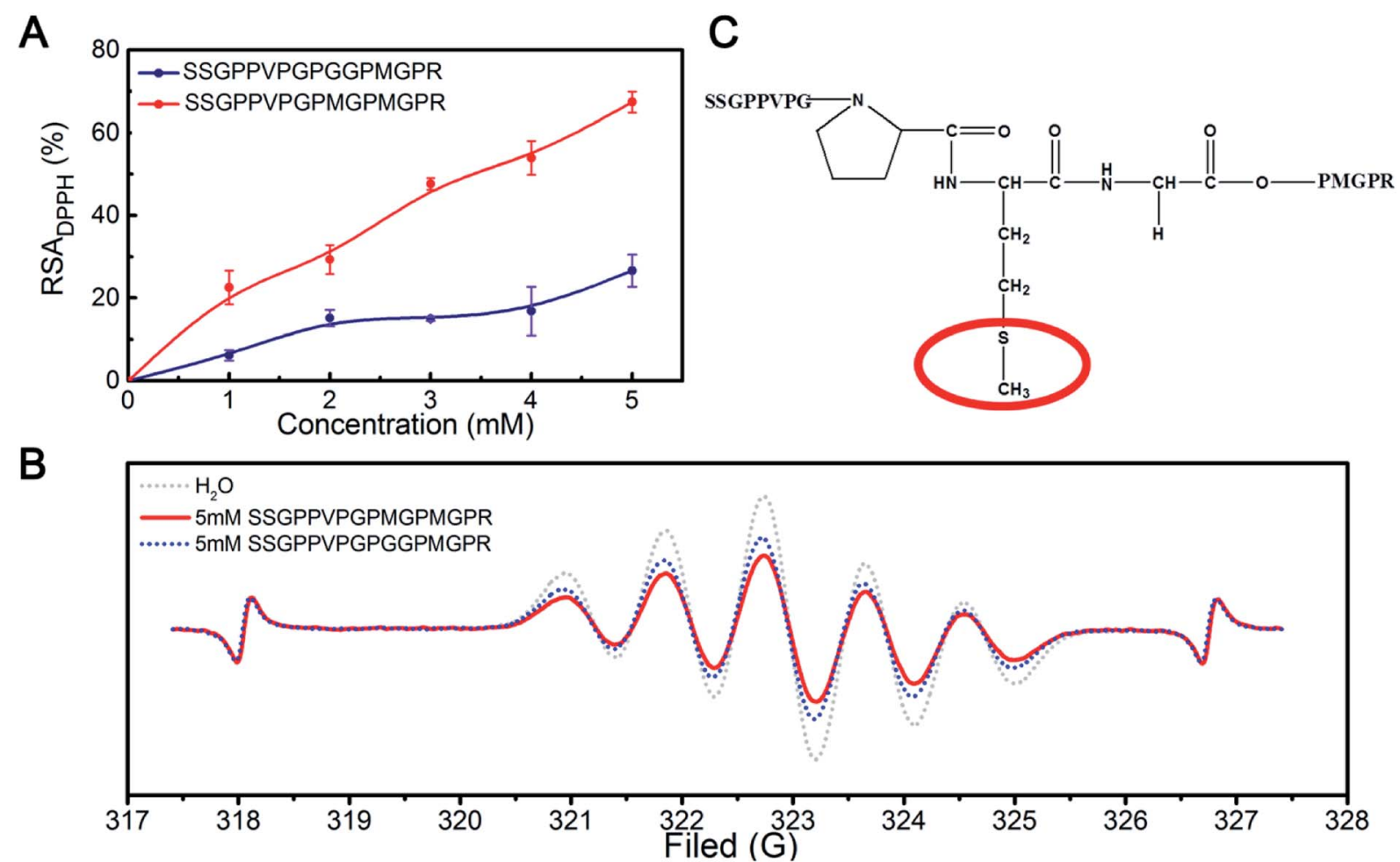

Fig. 6 (A) DPPH radical scavenging activity of the SSGPPVPGPMGPMGPR peptide and SSGPPVPGPGGPMGPR peptide; (B) ESR spectra of DPPH radicals in the presence of the SSGPPVPGPMGPMGPR peptide and SSGPPVPGPGGPMGPR peptide; (C) structure of the SSGPPVPGPMGPMGPR peptide.

\section{Conclusions}

Skipjack tuna bone has been used to obtain collagen peptides with high antioxidant activity. We found that a combination of trypsin and chymotrypsin can effectively hydrolyse the collagen of skipjack tuna bone to produce antioxidant hydrolysates. Among the antioxidant peptides isolated, the SSGPPVPGPMGPMGPR peptide exhibits particularly high antioxidant activity. In addition, a Met residue within this peptide chain was demonstrated to provide an active site for the scavenging of DPPH radicals. We believe that these findings will provide guidance for the development of peptides with high antioxidant activity from natural sources for functional foods.

\section{Conflicts of interest}

There are no conflicts to declare.

\section{Acknowledgements}

Financial support from the Fundamental Research Funds for the Central Universities (No. PYBZ1805) is gratefully acknowledged.

\section{Notes and references}

1 E. Hopps, D. Noto, G. Caimi and M. R. Averna, Nutr., Metab. Cardiovasc. Dis., 2010, 20, 72-77.
2 J. A. Leopold and J. Loscalzo, Free Radical Biol. Med., 2009, 47, 1673-1706.

3 T. Li, W. Xiang, F. Li and H. Xu, Biomaterials, 2017, 157, 17.

4 H. E. Seifried, D. E. Anderson, E. I. Fisher and J. A. Milner, J. Nutr. Biochem., 2007, 18, 567-579.

5 P. Yongvanit, S. Pinlaor and H. Bartsch, Parasitol. Int., 2012, 61, 130-135.

6 Z. Yu, Y. Yin, W. Zhao, J. Liu and F. Chen, Food Chem., 2012, 135, 2078-2085.

7 F. Li, T. Li, W. Cao, L. Wang and H. Xu, Biomaterials, 2017, 133, 208-218.

8 G. F. Rocha, F. Kise, A. M. Rosso and M. G. Parisi, Food Chem., 2017, 237, 350.

9 B. M. Kimatu, L. Zhao, Y. Biao, G. Ma, W. Yang, F. Pei and Q. Hu, Food Chem., 2017, 230, 58-67.

10 H. Cao, Q. Luo, H. Wang, Z. Liu, G. Li and J. Liu, RSC Adv., 2019, 9, 9289-9300.

11 L. Cai, X. Wu, Y. Zhang, X. Li, S. Ma and J. Li, J. Funct. Foods, 2015, 16, 234-242.

12 N. M. Sarbon, F. Badii and N. K. Howell, Food Hydrocolloids, 2018, 85, 311-320.

13 B. Liu, H. A. Aisa and A. Yili, Eur. Food Res. Technol., 2018, 244, 1615-1625.

14 Y. Zheng, Y. Li and G. Li, RSC Adv., 2019, 9, 5925-5936.

15 A. B. Shazly, Z. He, M. A. Elaziz, M. Zeng, S. Zhang, F. Qin and J. Chen, Food Chem., 2017, 232, 753-762.

16 B. Hernández-Ledesma, B. Miralles, L. Amigo, M. Ramos and I. Recio, J. Sci. Food Agric., 2010, 85, 1041-1048. 
17 K. Kawashima, H. Itoh, M. Miyoshi and I. Chibata, Chem. Pharm. Bull., 1979, 27, 1912.

18 R. Wu, C. Wu, D. Liu, X. Yang, J. Huang, J. Zhang, B. Liao and H. He, Food Chem., 2018, 248, 346.

19 B. Giménez, E. Pérez-Santin, M. C. Gómez-Guillén, A. Alemán and P. Montero, Food Chem., 2010, 125, 334-341. 20 D. H. Ngo, Z. J. Qian, B. M. Ryu, J. W. Park and S. K. Kim, J. Funct. Foods, 2010, 2, 107-117.

21 N. H. Herpandi, A. Rosma and W. A. W. Nadiah, Compr. Rev. Food Sci. Food Saf., 2011, 10, 195-207.

22 X. R. Yang, Y. Q. Zhao, Y. T. Qiu, C. F. Chi and B. Wang, Mar. Drugs, 2019, 17, 78.

23 S. Nalinanon, S. Benjakul, H. Kishimura and F. Shahidi, Food Chem., 2011, 124, 1354-1362.

24 S. Saidi, M. Saoudi and R. Ben Amar, Environ. Sci. Pollut. Res. Int., 2018, 25, 17383-17392.

25 A. I. Martinez-Gonzalez, Á. G. Díaz-Sánchez, L. A. Rosa, C. L. Vargas-Requena, I. Bustos-Jaimes and E. AlvarezParrilla, Molecules, 2017, 22, 669.

26 V. U. Ahmad, M. A. Lodhi, M. A. Abbasi and M. I. Choudhary, Fitoterapia, 2008, 79, 505-508.

27 J. Adler-Nissen, Enzymic hydrolysis of food proteins, Elsevier Applied Science Publishers, 1986.

28 L. Chao and S. Jiao, Biomacromolecules, 2014, 15, 436.

29 L. D. Piu, A. Tassoni, D. I. Serrazanetti, M. Ferri, E. Babini, D. Tagliazucchi and A. Gianotti, Food Chem., 2014, 155, 199-206.

30 A. J. Kirby and R. J. Schmidt, J. Ethnopharmacol., 1997, 56, 103-108.

31 Y. Ma and Y. L. Xiong, J. Agric. Food Chem., 2009, 57, 43724380.
32 F. Bamdad and L. Chen, Mol. Nutr. Food Res., 2013, 57, 493503.

33 J.-R. Han, J.-N. Yan, S.-G. Sun, Y. Tang, W.-H. Shang, A.-T. Li, X.-K. Guo, Y.-N. Du, H.-T. Wu and B.-W. Zhu, Food Chem., 2018, 261, 337-347.

34 A. A. Karim and R. Bhat, Food Hydrocolloids, 2009, 23, 563576.

35 E. Babini, D. Tagliazucchi, S. Martini, P. L. Dei and A. Gianotti, Food Chem., 2017, 228, 186.

36 H. Guo, Y. Kouzuma and M. Yonekura, Food Chem., 2009, 113, 238-245.

37 R. J. Elias, S. S. Kellerby and E. A. Decker, Crit. Rev. Food Sci. Nutr., 2008, 48, 430.

38 C. F. Chi, B. Wang, Y. M. Wang, B. Zhang and S. G. Deng, J. Funct. Foods, 2015, 12, 1-10.

39 H. Y. Luo, B. Wang, Z. R. Li, C. F. Chi, Q. H. Zhang and G. Y. He, LWT-Food Sci. Technol., 2013, 51, 281-288.

40 L. Gu, M. Zhao, W. Li, L. You, J. Wang, H. Wang and J. Ren, Food Chem. Toxicol., 2012, 50, 4085-4091.

41 Y. Yang and S. Mu, Electrochim. Acta, 2013, 109, 663-670.

42 J. Li, B. Kuttich, M. Gallei, J. Elbert, M. Rehahn and B. Stühn, Polymer, 2013, 54, 5703-5711.

43 Y. Ma, Y. Wu and L. Li, Food Chem., 2018, 264, 108-117.

44 E. Babini, D. Tagliazucchi, S. Martini, L. D. Più and A. Gianotti, Food Chem., 2017, 228, 186-196.

45 M. Memarpoor-Yazdi, A. Asoodeh and J. K. Chamani, J. Funct. Foods, 2012, 4, 278-286.

46 S. Knasmüller, W. Parzefall, R. Sanyal, S. Ecker, C. Schwab, M. Uhl, V. Mersch-Sundermann, G. Williamson, G. Hietsch and T. Langer, Mutat. Res., Fundam. Mol. Mech. Mutagen., 1998, 402, 185-202. 